\title{
Psychiatric disorders and traumatic brain injury
}

\author{
Marcelo Schwarzbold' \\ Alexandre Diaz' \\ Evandro Tostes Martins ${ }^{2}$ \\ Armanda Rufino' \\ Lúcia Nazareth Amante ${ }^{1,3}$ \\ Maria Emília Thais' \\ João Quevedo4 \\ Alexandre Hohl' \\ Marcelo Neves Linhares $1,5,6$ \\ Roger Walz',6
}

'Núcleo de Pesquisas em Neurologia Clínica e Experimental (NUPNEC),

Departamento de Clínica

Médica, Hospital Universitário,

UFSC, Florianópolis, SC, Brazil;

${ }^{2}$ Unidade de Terapia Intensiva,

Hospital Governador Celso

Ramos, Florianópolis, SC, Brazil;

${ }^{3}$ Departamento de Enfermagem,

UFSC, Florianópolis, SC, Brazil;

${ }^{4}$ Laboratório de Neurociências,

UNESC, Criciúma, SC, Brazil;

${ }^{5}$ Departamento de Cirurgia, Hospital Universitário, UFSC, Florianópolis, SC, Brazil; ${ }^{6}$ Centro de Cirurgia de Epilepsia de Santa Catarina (CEPESC), Hospital Governador Celso Ramos,

Florianópolis, SC, Brazil
Correspondence: Marcelo Schwarzbold/ Roger Walz

NUPNEC, Departamento de Clínica

Médica, Hospital Universitário, 3

andar, Universidade Federal de Santa

Catarina - UFSC, CEP 88.040-970,

Campus Universitário, Trindade,

Florianópolis, SC, Brazil.

Tel: +55 4837219149

Fax: +55 4837219014

Email:schwlib@gmail.com/

rogerwalz@hotmail.com

\begin{abstract}
Psychiatric disorders after traumatic brain injury (TBI) are frequent. Researches in this area are important for the patients' care and they may provide hints for the comprehension of primary psychiatric disorders. Here we approach epidemiology, diagnosis, associated factors and treatment of the main psychiatric disorders after TBI. Finally, the present situation of the knowledge in this field is discussed.
\end{abstract}

Keywords: psychiatric disorders, traumatic brain injury, neuropsychiatry, diagnostic, epidemiology, pathophysiology

\section{Introduction}

One of the first detailed reports of psychiatric symptoms following traumatic brain injury (TBI) was the famous case of Phineas Gage, a construction worker who, in 1848, survived an accident in which an iron bar went through his skull, seriously damaging the frontal lobe. His doctor, John Harlow, described his personality changes: from being a responsible and socially well-adapted man, Gage became negligent, irreverent and profane, unable to take responsibility (Damásio et al 1994). The systematized study of the topic was only established at the beginning of the 20th century by Adolf Meyer. He published comprehensive case reports about patients who presented behavior disturbances after head injuries and proposed a set of disorders called "traumatic insanities", which included consciousness alterations, psychosis, and neurological symptoms (Neylan 2000). Since then, many efforts have been done to improve knowledge in this area, but it still constitutes a fertile field for research, with many gaps to be filled. In spite of considerable amount of papers in the literature, their levels of scientific evidence are frequently low. The importance of the theme is justified due to the high incidence of TBI and to the personal suffering and social cost in consequence of this pathology.

The present review encloses data on epidemiology, diagnosis, associated factors and treatment of psychiatric disorders after TBI. Delirium, amnesic disorder, dementia, and postconcussional syndrome are not included here. Although they are described in the psychiatric diagnostic manuals, these conditions are more strongly associated to a general medical approach, which diverges from the proposed aim of this review.

\section{General considerations about TBI}

The difficulties in evaluating TBI start when defining its severity. The classifications usually consider data of the clinical history, physical exam or neuroimaging. A widely accepted severity classification uses the Glasgow Coma Scale (GCS), which is applied during the patient's primary evaluation. A 13 to 15 score in GCS indicates a mild TBI, from 9 to 12 a moderate one and from 3 to 8 a severe TBI (Teasdale and Jennett 1974). Another commonly used classification is based on the lack of consciousness and amnesia (The Mild Traumatic Brain Injury Committee of the Head Injury Interdisciplinary Special Interest Group of the American Congress of Rehabilitation Medicine 1993). 
A TBI can be penetrating or closed, depending on if there was brain tissue exposition or not. The central nervous system injuries can be primary or secondary. Primary injuries are related to the tissue impairment which results directly from the impact forces. These injuries can be localized, such as a laceration of the brain parenchyma, or diffuse lesions, as in the diffuse axonal injury. The secondary injuries are developed subsequently as tissue response to the primary injuries or to systemic events (Bárcena-Orbe et al 2006). Examples of secondary injuries are inflammation, ischemia, lack of blood flow auto regulation, and glial proliferation (Nortje and Menon 2004).

The efficient intervention on clinical and surgical conditions that can contribute for the emergence of secondary injuries is an important determining of the early or long term prognostic in TBI patients. The conditions that allow intervention include intracranial hypertension, seizures, deep venous thrombosis with lung embolism, systemic or central nervous system infections, anemia, hypoxia and shock, among others (Bowles 2007). Common sense indicates that early identification and intervention on emotional and behavioral disturbances may also improve the life quality of these patients (Rapoport et al 2003).

\section{TBI epidemiology}

TBI is a worldwide public health problem. It has already been named the "silent epidemic" because of the limited popular knowledge about the issue and of its symptoms, such as memory and cognitive problems, which may not be immediately evident. At least 1.4 million cases occur each year in the United States. Among them, about 50,000 are fatal, 235,000 are admitted to hospitals and 1.1 million are treated and released from emergency departments (Langlois et al 2006). Approximately 5.3 million people live suffering from long-term disabilities as a result of TBI. The direct and indirect annual costs were estimated in more than 56 billion dollars (Binder et al 2005). In Europe, Tagliaferri and colleagues (2006) calculated an annual incidence of 235 cases in 100,000 inhabitants based on studies from different countries. The same authors estimated that almost 6.3 million people live with some level of disability, impairment or handicap related to TBI. In the south of Europe, the main causes for TBI are traffic accidents. In the north of Europe, the major causes are falls, mainly related to alcohol use (Tagliaferri et al 2006). TBI rates are consistently higher in men than in women. Most of the cases occur among children, adolescents, and young adults, with the second peak among the elderly people. The causes are different depending on the age group: traumas related to falls are more frequent among children and older adults, and traumas related to traffic accidents and violence are more common among adolescents and young adults. In general, more than two thirds of the reported cases of TBI are mild, dividing equally the rest of them between moderate and severe ones (Tagliaferri et al 2006).

In the developing countries, including Brazil, as a general rule there is a lack of epidemiologic studies. In a large Brazilian city, a research using data from a specialized center estimated a yearly TBI incidence of 341 per 100,000 inhabitants (Massini 1994). The author attributed this high number to the elevated rate of traffic accidents. The traffic-vehicular cause is responsible for more than $70 \%$ of the cases in the city where the authors of this revision work (unpublished data). Regarding gender and age characteristics, apparently there are similarities between Brazil and other countries (Melo et al 2004). The importance of regional epidemiology has already been pointed out as the base for planning assistance to TBI (Servadei et al 2002).

The epidemiologic data of psychiatric disorders after TBI vary widely in the literature. The rates for incidence or prevalence are usually higher than in general population, but some limitations must be discussed. In the United Kingdom, Deb and colleagues (1999) evaluated 164 patients through a structured interview based on the International Classification of Diseases 10th Revision (ICD-10) one year after TBI. They found that $21.3 \%$ of the sample received a psychiatric diagnosis. Rates for depression (13.9\%) and panic disorder (9\%) were significantly higher than in general population. The risk factors that were considered for a psychiatric diagnosis were: young age, low educational level, low score in the Glasgow Outcome Scale and previous history of TBI, psychiatric disease or alcohol use. The inclusion criteria demanded evidences of brain harm (lack of consciousness, GCS lower than 15 , radiological signals of brain damage), not only a head injury. Although most of patients in the sample had a mild TBI, it is possibly to argue that these inclusion criteria may have excluded those patients who represent the largest part of general TBI cases, for whom hospitalization is not needed. In Finland, Koponen and colleagues (2002) identified patients up to 30 years after TBI through the medical records, then applied a structured psychiatric method based on Diagnosis and Statistical Manual of Mental Disorders 4th Edition (DSM-IV). The findings showed rates as high as $48.3 \%$ for any psychiatric disorder starting after the traumatism and major depression was the most common diagnosis $(26.7 \%)$. The authors concluded that TBI may cause decades-lasting 
vulnerability to psychiatric disorders in some individuals. Nevertheless, the sample was composed only by patients who had been referred to neuropsychological evaluation and then it may represent a more specific population. In the northwest of the United States, Fann and colleagues (2004) found a psychiatric diagnostic in $49 \%$ of severe and moderate TBI patients, and $34 \%$ of the mild one, compared to $18 \%$ within the comparison group. The cases were identified through the diagnostic codes of a wide data bank. An evident limitation of this procedure is the lack of a structured diagnosis method.

\section{Depression}

\section{Diagnosis and epidemiology}

Major depression is considered a common sequel in TBI survivors. Kim and colleagues (2007) revised in detail the epidemiology of depression after TBI and reported incidence rates of 15.3 to $33 \%$ and prevalence rates of 18.5 to $61 \%$. Several reasons for this wide variety can be mentioned. For instance, studies used a variety of diagnostic criteria and instruments and evaluated patients at different times after TBI. Studies are also frequently limited by small samples, loss to follow-up, and referral bias. Furthermore, depressive symptoms are multifactorial and can represent from transitory responses to stressing situations up to clearly pathological conditions. After a catastrophic injury, boundaries between depression, adjustment disorder and grief may become less demarcated (Rosenthal et al 1998). Additionally, it can be difficult to differentiate somatic manifestations of depression from symptoms which are directly caused by TBI or by other concomitant general medical conditions. Examples of overlapped symptoms are fatigue, decreased involvement in activities, insomnia, lack of appetite and concentration. These limitations may occur even using the classical instruments for measuring depression (Sliwinski et al 1998). Finally, in some cases reverse causality may also be possible (Vassalo et al 2007).

A good estimation for incidence for depression after TBI was provided by Jorge and colleagues (2004). They followed 91 patients for 6 months using the Structured Clinical Interview for DSM Disorders (SCID) (First et al 1996) and found that $33 \%$ met major depression criteria at some point during the follow-up, compared with $7.4 \%$ within the noncranial traumatism group. For a reasonable estimation of prevalence, a rate of $27 \%$ was found in the multicenter study by Seel and colleagues (2003), which evaluated a multicenter sample of 666 patients in an average of 35.3 months after TBI through the Neurobehavioral Functioning Inventory (Kreutzer et al 1996a). The predominant symptoms were lack of energy ( $29 \%$ of the cases), difficulties for concentration and irritability (28\% each).

\section{Neuropsychiatric findings}

There are few works which evaluated the relation between depression after TBI and damage in relatively specific brain regions. The findings were frequently inconsistent. In the already mentioned study by Jorge and colleagues (2004), a relationship between depression and reduction of the left prefrontal grey matter volume in the neuroimaging exams was found, especially in the ventrolateral and dorsolateral regions. In a 66 sample of TBI survivors, Fedoroff and colleagues (1992) found a relation between depression and lesions in dorsolateral prefrontal cortex and left basal ganglia in the acute phase of TBI. However, the same patients were followed by Jorge and colleagues (1993a) and no relation was found one year later. Levin and colleagues (2005) followed 129 mild TBI patients and found that the presence of any abnormalities on computed tomography (CT) scan predicted depression after 3 months. Paradiso and colleagues (1999) compared two small groups of patients with lateral and medial frontal lobe lesions, including TBI survivors. After 3 months of follow-up, patients with lateral damage showed greater severity of depressive symptoms and apathy.

It has been proposed, at a theoretical level, that the rupture of neural circuits involving the prefrontal cortex, amygdala, hippocampus, basal ganglia, and thalamus may be related to the development of depression due TBI. During traumatism, diffuse axonal injury and damage located precisely in the frontal and anterior temporal regions are frequent, which may be an explanation for the high rate of mood disorders among these patients (Jorge and Starkstein 2005). The classic monoaminergic hypothesis of depression may also be useful for explaining depressive symptoms due TBI. Low levels of serotonin, for example, are classically associated to emotional changes, disinhibition and aggression, which are common symptoms of mood disorders after TBI. Disturbances in the neurotransmission systems, including serotonin, glutamate and dopamine were described in animal models and in TBI patients (Soblosky et al 1992; Jorge and Starkstein 2005). Saran (1985) found that depression in patients who had suffered minor closed head injury did not respond well to amitryptiline and phenelzine in comparison to depression in nonhead injured patients. Moreover, depression after minor closed head injury was not correlated to abnormal results in the dexamethasone suppression test. The small samples were an evident limitation of this study (10 and 12 patients, respectively). 
The hippocampus is an anatomic region vulnerable to TBI. Disruption in hippocampal functioning and morphology has been described in cognitive and depressive disorders (Campbell and MacQueen 2004). Studies on animals found alterations in the hippocampal neurogenesis and gliogenesis after experimental traumatism (Rola et al 2006; Richardson et al 2007). Jorge and colleagues (2007) measured hippocampal volume through magnetic resonance imaging (MRI) in a sample of 37 TBI survivors, finding lower bilateral hippocampal volume and reduction of left frontal grey matter in patients who had developed depression. Lower hippocampal volume was not associated to cognitive impairment, but predicted a poor vocational outcome. The authors suggested that neuronal and glial elements first affected by trauma may be additionally compromised by changes related to depression, contributing to chronic behavioral problems. Perna and colleagues (2003) proposed at the theoretical level that the induction of hippocampal neurogenesis induced by the antidepressants may not only improve the depressive symptoms but also the cognitive deficits in TBI survivors (Perna et al 2003).

\section{Other findings}

Patients who develop depression after TBI may have a psychosocial profile. Poorer social functioning was found by Gomez-Hernandez and colleagues (1997) and Fedoroff and colleagues (1992). The first author reported also higher levels of dissatisfaction with work. Unemployment was a consistent finding in several studies (Seel et al 2003; Dikmen et al 2004; Jorge et al 2004). Other psychosocial factors associated to depression after TBI that were found included low economic status (Jorge et al 2004), less education (Dikmen et al 2004) and lack of close personal relationships (Gomes-Hernandez et al 1997).

Psychiatric comorbidity may be common in depression after TBI. In the study by Dikmen and colleagues (2004), preinjury alcohol-related problems were more frequent in TBI patients with depression. As in the general population, anxiety and depression frequently coexist in TBI survivors. Jorge and colleagues (1993c) diagnosed generalized anxiety in $41.2 \%$ of a sample of depression after TBI patients. The duration of the anxious depression was longer than 7.5 months, compared to 1.5 months for depression without significant anxiety. Anxious depression was related to injuries in the right hemisphere, while isolated depression was more correlated to anterior injuries on the left. The authors suggested that depression after TBI with and without significant anxiety are perhaps different conditions, with distinct etiology. The same authors found aggressive behavior as a common symptom in these patients (Jorge et al 2004).

\section{Treatment}

In the literature there are not sufficient evidences that make possible the elaboration of standard recommendations for the treatment of depression after TBI, although the pharmacological intervention is emphasized. Most of the available works enclose few patients, or they are not controlled. Citalopram and sertraline are especially advantageous, because of the lower profile of side effects and drug interaction (Turnes-Stokes and MacWalter 2005). There is a larger open-label study for citalopram which supports the use of the drug (Rapoport et al 2008). The use of fluoxetine, paroxetine, venlafaxin, minalcipran, amitryptiline, desipramine, bupropion, moclobemide, and methylphenidate has been reported, presenting generally positive results (Alderfer et al 2005; Warden et al 2006). However, anticholinergic effects of tricyclic antidepressants can exacerbate cognitive impairment. Patients with impulsiveness and poor judgment can have difficulties in following dietary restrictions demanded for irreversible monoamine oxidase inhibitors. Electroconvulsive therapy, a highly efficient treatment in primary depression, obtained positive results in case series of depression after TBI, although it presented a transitory worsening of the cognitive deficits (Kant et al 1999). Hence depression after TBI is associated to psychosocial factors, specific interventions in this area are frequently necessary. Family and social support can reduce the caregivers' weariness and psychotherapy adapted to the cognitive limitations may be useful for these patients (Rosenthal et al 1998; Alderfer et al 2005).

\section{Mania}

\section{Diagnosis and epidemiology}

A variety of diagnostic criteria, such as DSM-III, DSM-III-R, DSM-IV, and Research Diagnostic Criteria, have been used to define mania after TBI (Kim et al 2007). Some authors included the condition among the disinhibition syndromes, taking into account the overlapping symptoms and possibly common pathophysiological mechanisms (Starkstein and Robinson 1997). In the lack of ideal criteria able to differentiate mania clearly attributable to TBI from mania simply observed following TBI, the close temporal relationship in the absence of other etiology may be the best approach (Kim et al 2007). Mania due to TBI should be also suspected when there is an atypical age for the beginning 
of the symptoms and lack of personal or family history of psychiatric disorders (Riess et al 1987). Mania due to TBI may present more aggression, more irritable moods, and less euphoria (Shukla et al 1987).

Van Reekum and colleagues (2000) revised data from several studies and found a prevalence of $4.2 \%$ for mania which was probably directly caused by TBI. Jorge and colleagues (1993b) evaluated 66 TBI patients through DSM-IV criteria and found a rate of $9 \%$ for mania incidence within 12 months of follow-up. The extent of the symptoms was relatively short (around two months). However, these data do not allow firm conclusions about the incidence and prevalence rates of mania after TBI (Kim et al 2007). Van Reekum and colleagues (1996) found a gender difference, with 4 of 8 males, versus 1 of 10 females, developing bipolar symptoms after TBI.

\section{Neuropsychiatric findings}

Studies approaching neuropsychiatric aspects of mania after TBI are rare and limited by sample size, which may reflect the relatively low incidence of the condition. In the study by Jorge and colleagues (1993b), the development of mania was associated to multifocal brain lesions, mainly in the temporal basal poles. Association to trauma severity, cognitive impairment and seizures was not found. However, another study related mania after TBI to seizures (Shukla et al 1987). A case report by Murai and Fujimoto (2003) described a patient who developed rapid cycling bipolar symptoms after a circumscribed lesion in the left temporal pole due to TBI. Other studies related the presence of lesions in temporal areas and in the orbitofrontal cortex, mainly in the right hemisphere (Starkstein et al 1988; Robinson et al 1999).

Neuroanatomical mechanisms have been hypothesized in order to explain the etiology of mania due TBI. Starkstein and colleagues (1987) suggested that the genetic predisposition for mood disorders and focal lesions in areas that are connected to the limbic system in the right hemisphere, or anterior subcortical atrophy, may provide the necessary factors for the developing of the symptoms. Similarly, in primary mania it has been suggested that the emotional disturbance may be a result of the lack of the inhibitory function of the frontal cortex on subcortical limbic structures, through mild abnormalities in these circuits (Adler et al 2006). Hyperintensities found in the subcortical white matter in some individuals with bipolar disorders may indicate diffuse lesions in circuits which are involved in mood regulation (Frey et al 2004). Starkstein and Robinson (1997) also demonstrated the importance of lesion lateralization in animal models: right hemisphere injuries produced modifications in the norepinephrine and dopamine systems that did not occur in left hemisphere experimental injuries (Starkstein and Robinson 1997).

\section{Other findings}

There are few positive findings in literature regarding psychosocial factors in mania after TBI. This may reflect a stronger biological basis for the symptoms, in comparison to depression, for instance. In the already cited study by Jorge and colleagues (1993b), patients with and without mania did not differ in previous level of social functioning or in personal and family history of psychiatric disorders. However, another study found a relation between mania and family history of mood disorders (Robinson et al 1988). DelBello and colleagues (1999) evaluated retrospectively individuals convicted of sexual offenses and found that subjects with bipolar disorder were more likely to have a TBI than those without bipolar disorder and control patients.

\section{Treatment}

There is limited evidence in the literature about specific pharmacotherapy for mania after TBI. Open label studies described positive results when using valproic acid and lithium, while case reports pointed out the usefulness of quetiapine, carbamazepine, clonidine, and electroconvulsive therapy (Warden et al 2006; Oster et al 2007). In addition, it is possible to speculate that the neural protective effects of lithium may be useful when used in patients suffering from acquired brain injury (Wada et al 2005). Isolated psychotherapy is not considered efficient for mania after TBI, although it can have a complementary role (Schneck 2002). According to the common sense, general interventions of social and family support in the rehabilitation can benefit these patients.

\section{Obsessive-compulsive disorder Diagnosis and epidemiology}

The diagnosis of obsessive-compulsive disorder (OCD) in TBI survivors requires special attention, since manifestations of other conditions frequently associated to TBI can complicate the identification of the disorder. For example, some patients may show repetitive behaviors due to memory problems, or perseveration as a consequence of executive deficits, becoming anxious when they become aware of their difficulties (Coetzer 2003). In contrast, patients with impaired self-awareness may not realize obsessions and compulsions as excessive or unreasonable. 
Berthier and colleagues (1996) evaluated patients with OCD symptoms which started after brain lesions (including TBI) and found less family history and older age of onset than primary OCD patients. In a later study, Berthier and colleagues (2001) assessed 10 referred patients who had developed OCD after TBI and found peculiar symptoms of obsessive slowness in 3 cases and compulsive exercise practice in 3 cases also ( 1 patient had both symptoms). The patients that presented obsessive slowness showed a worse performance in neuropsychological tests for executive function, memory, and language.

OCD symptoms seem to be uncommon in TBI survivors. Deb and colleagues (1999) found a prevalence of 1.6\%, a rate similar to the general population's one. Van Reekum and colleagues (1996) found only 1 case among 18 evaluated patients. A higher prevalence of $15 \%$ was found by Hibbard and colleagues (1998), but the self-selected sample may have led to an overestimated rate. We could not find studies approaching incidence of OCD after TBI in a more strict definition. However, there are several case reports and series richly described in literature, giving some evidence for a traumatic etiology in some cases (McKeon et al 1984; Jenike and Brandon 1988; Kant et al 1996; Childers et al 1998; Bilgic et al 2004; Ogai et al 2005).

\section{Neuropsychiatric findings}

There are only case reports and small series in literature describing the factors associated to OCD after TBI. Many of these cases presented patients with lesions in frontal and subcortical areas. Orbitofrontal cortex, caudate nucleus, and anterior cingulate cortex were areas where structural lesions or functional abnormalities were frequent demonstrated (Berthier et al 2001; Bilgic et al 2004; Ogai et al 2005). However, cases of mild TBI without any evident structural damage were also frequently reported. Convergent evidences indicate the involvement of the same mentioned areas in the physiopathology of primary OCD (Gabriel and Rauch 2000; Grados 2003). The pattern of cognition deficits in the series by Berthier and colleagues (2001) also suggested dysfunction of the frontal-subcortical circuits. Deficits in the executive function seem to be the main cognitive impairments in primary and secondary OCD (Coetzer 2004).

\section{Other findings}

As far as we know, no studies approached psychosocial factors in OCD after TBI. This is not surprising, considering the relatively low incidence of the symptoms and the subsequent small size of the samples. Furthermore, OCD is in general considered as a condition with a strong biological basis. Nevertheless, obsessive-compulsive symptoms have potential to disrupt the rehabilitation process (Grados 2003).

Psychiatric comorbidity may be also common in patients with OCD after TBI. In the series by Berthier and colleagues (2001) there were elevated rates for depression (90\%), posttraumatic stress disorder (PTSD) (70\%), panic attacks (40\%) and aggressive behavior (30\%).

\section{Treatment}

The current treatment for OCD after TBI treatment is similar to the primary OCD treatment. Individuals who have preserved cognitive capacity can benefit by structured cognitive-behavioral therapy (CBT). In regard to pharmacotherapy, the effectiveness of serotonergic antidepressants for general OCD is well known. The more advantageous profile of SSRI side effects compared with clomipramine can be particularly important for TBI patients (Stengler-Wenzke and Muller 2002; Grados 2003).

\section{Posttraumatic stress disorder Diagnosis and epidemiology}

Several studies have discussed the influence of TBI severity and posttraumatic amnesia on the epidemiology of PTSD after TBI, taking into account that the formation of pathological memories is considered as a precondition for the developing of PTSD symptoms (Elbert and Schauer 2002).

Some authors suggested that mild TBI and PTSD might be mutually exclusive disorders. Sbordone and Liter (1995) asked 70 patients who had been previously diagnosed as having either mild TBI or PTSD to describe in detail the symptoms and the chronological history of the traumatic event. None of the mild TBI patients could provide a highly detailed and emotionally charged recollection or show PTSD symptoms. Conversely, all the PTSD patients could describe the traumatic event. Similarly, in a study involving consecutive road traffic accidents victims in general, Mayou and colleagues (1993) did not find PTSD symptoms in subjects who had been briefly unconscious and had amnesia about the accident.

However, other studies were able to find occurrence of PTSD after mild TBI. Bryant and Harvey (1998) followed 79 consecutive mild TBI patients using structured diagnosis interviews and found acute stress disorder (ASD) in 13.9\% of the subjects 1 month after the trauma. Six months later, $81.8 \%$ of ASD cases met criteria for PTSD, contrasting with $11.5 \%$ of those who did not develop ASD. The incidence of 
PTSD in the entire sample was $24 \%$. Creamer and colleagues (2005) evaluated 307 consecutive patients 12 months after mild TBI through a structured interview and found a PTSD prevalence of $10 \%$. Nonsignificant differences were apparent among patients who had full recall, partial recall, and no recall of the traumatic event. According to the authors, these data indicate that PTSD may develop despite the occurrence of posttraumatic amnesia.

Some studies approached directly the importance of posttraumatic amnesia. Gil and colleagues (2005) followed a cohort of 120 patients until 6 months after mild TBI and found an incidence of $14 \%$. Subjects who had memories of the traumatic event were more likely to present PTSD. After logistic regression analysis, presence of memory of the traumatic event within the first 24 hours was a strong predictor of PTSD. Glaesser and colleagues (2004) evaluated 46 patients of a rehabilitation clinic and found a higher prevalence of PTSD in subjects that were not unconscious during the traumatic event $(27 \%)$, compared to individuals who were unconscious ( $3 \%, 1$ of 31 patients). Furthermore, intrusive memories were more frequent in patients who had not been unconscious.

The occurrence of PTSD has been also reported after moderate and severe TBI. Bombardier and colleagues (2006) followed a sample of 125 consecutive TBI patients who had a moderate and severe TBI or an abnormal CT result. After 6 months, the cumulative incidence was $11.3 \%$ and the prevalence was $5.6 \%$, suggesting a relatively short course of PTSD in this population. Bryant and colleagues (2000) evaluated 96 TBI patients who had a mean value for posttraumatic amnesia of 36.97 days and a mean score of GCS of 8 , indicating that on average they had no solid recall of events in the first month after traumatism. The prevalence of PTSD was $27.1 \%$, with a minority of these patients $(19.2 \%)$ reporting intrusive memories and most of them presenting emotional reactivity $(96.2 \%)$.

The findings described above allow us to conclude that PTSD can occur even after severe TBI with extended posttraumatic amnesia, but they also suggest that posttraumatic amnesia may have a protective role. Moreover, patients who were unconscious during the traumatic event may have less reexperiencing symptoms (Bryant et al 2000; Glaesser et al 2004; Gil et al 2005).

Self-reported diagnostic instruments may have limited use in PTSD after TBI. Confusion can be caused by overlapped symptoms such as poor concentration, hyperarousal, irritability, reduced involvement in activities, or even amnesia. In the study by Sumpter and McMillan (2005), the rate for PTSD in self-reported questionnaires was above $40 \%$, contrasting with the $3 \%$ rate in structured interviews. No significant differences were found between those who were pursuing litigation and those who were not.

\section{Neuropsychiatric findings}

No studies have enclosed the identification of lesions in specific brain circuits in PTSD after TBI. In the interesting study by Sojka and colleagues (2006), the seric increase of the astrocytic protein S-100B (a biochemical marker of brain tissue injury) in the TBI acute phase was related to the presence of PTSD one year later. This may reflect the complexity of the interaction between response to stress and brain tissue injuries.

As described above, most studies have approached the relationship between PTSD and posttraumatic amnesia. This is an opportunity for the understanding of pathophysiology of traumatic memories (Gil et al 2006). In terms of declarative memory, it is possible that some patients keep information for short periods of cognitive function preservation during the traumatic event. These "islands of memory" would form the base of the subsequent traumatic recollections. For example, a patient can have intrusive images of the circumstances immediately previous or subsequent to the accident, or of short scenes when waiting for rescue. Regarding nondeclarative memory, the processing of the information emotionally charged can occur directly through amygdala, hippocampus and other related structures. Therefore, it is possible that some characteristics of the traumatic event are coded even during the periods of consciousness disturbances. Later on, similar situations would reactivate these memories (Bryant 2001). Conditioned fear is another implicit mechanism for traumatic memories. Psychophysiological studies provide indirect support for this finding. The high heart frequency in the TBI acute phase, for example, was found as a predictor of PTSD (Bryant et al 2004). Finally, case descriptions in the literature show that individuals can rebuild memories about the traumatic event (Bryant 1996). For instance, a patient can have intrusive images of the accident or of stories that have been reported by someone else, even if they do not correspond to what actually happened.

\section{Other findings}

Bryant and colleagues (1999) found reduced quality of life and poorer productivity functioning among TBI survivors who had developed PTSD. Patients with chronic pain had also more PTSD symptoms. Willians and colleagues (2002) evaluated 66 patients from brain injury rehabilitation services 
and found that PTSD was positively correlated to external attribution to others of causality for the traumatic event and negatively correlated to level of insight. The authors suggested that the lack of insight may have had a protective role, or simply the patients were not able to report the symptoms. Subjects did not differ in intelligence quotient, memory impairment, or educational background. In the already cited study by Bombardier and colleagues (2006), assault as a traumatic event was associated to PTSD, as well as the use of stimulant drugs (cocaine, amphetamine) and lower educational level. Comorbidity with depression and anxiety is a consistent finding in PTSD after TBI (Bryant et al 1999; Glaesser et al 2004; Gil et al 2005; Bombardier et al 2006).

\section{Treatment}

CBT is employed in PTSD in general, and it is also considered useful in PTSD after TBI, although the available evidences are essentially case reports (McMillan et al 2003). If a patient has relevant cognitive sequelae, specific adaptations may be required. For example, techniques that demand attention focused in images or memories about the traumatic event may be not possible in patients who do not have declarative memories about it. In this case, the patient would have to be exposed to other type of stimulus (Bryant 2001). It was also suggested that CBT may prevent development of PTSD in ASD patients (McMillan et al 2003).

There are not specific recommendations for pharmacotherapy of PTSD after TBI, except for the care due to these patients' tendency to suffer side effects. Useful drugs for PTSD in general, such as antidepressants (especially SSRIs), atypical antipsychotics and adrenergic blockers are treatment options (Vieweg et al 2006). General medical conditions and psychiatric comorbidities which might collaborate in the maintenance of the posttraumatic symptoms must also receive treatment (Joseph and Masterson 1999).

\section{Psychotic disorders Diagnosis and epidemiology}

Psychosis after TBI seems to be rare. David and Prince (2007) reviewed the epidemiology of psychotic symptoms associated to head injuries, including the first studies about the topic. Incidence rates varied from $0.1 \%$ to $9.8 \%$. Many of the earliest studies evaluated large cohorts, but the generalization of the results is limited by retrospective designs, differences among ancient and current diagnostic criteria and use of samples that have specific characteristics, such as war veterans (Achte et al 1969). Van Reekum and colleagues (2000) reviewed data from recent studies and found a prevalence of $0.7 \%$. Since there are no clear operational criteria to define traumatism as an etiology, the main limitation of the literature has been the difficulty to distinguish patients with psychosis attributable to TBI from patients with primary psychosis who have suffered a head injury (Kim et al 2007). Confounding seems to be especially important in mild TBI cases. For instance, there are works that demonstrated that psychotic patients may be more predisposed to suffer traumatisms (Fann et al 2004). The idea that a genetic background for schizophrenia (not necessarily the manifest disorder) would increase the exposition to TBI, and the traumatism would increase the risk of manifestation of the disorder later on (Malaspina et al 2001) has already been proposed.

The DSM-IV-TR criteria for psychosis due general medical condition point out a temporal relationship between TBI and the onset of the symptoms. In the series by Fujii and Ahmed (2002a), more than half of the cases started during the first year after the traumatism. However, some studies found latency periods that lasted more than 50 months (Sachdev et al 2001; Fujii and Ahmed 2001), or even several decades (Achte et al 1969). In the acute phase of TBI, psychotic symptoms are probably delirium manifestations.

Another diagnostic recommendation in DSM-IV-TR is the evaluation of atypical features of psychosis. Literature findings about the characteristics of psychosis after TBI derive essentially from studies with small samples and possible selection bias. Sachdev and colleagues (2001) evaluated 45 patients with schizophrenia-like psychosis after TBI who were referred for neuropsychological testing. Delusions were the most frequent clinical manifestation and the content was mainly persecutory ( $56 \%$ of the total of individuals suffering from delusions), reference (22\%), control (22\%), and grandiosity (20\%). Hallucinations were more frequent in those subjects who suffered from delayed psychosis (ie, more than 2 years after the traumatism) and most of the times were auditory ( $84 \%$ of the total of individuals suffering from hallucinations) and visual (20\%). Voices commenting on the patient's behavior, which are classically associated to schizophrenia, were also frequent. Aggressive behavior was found in $40 \%$ of the sample. Negative symptoms, disorganization, and catatonia were unusual features. In the study by Fujii and Ahmed (2001), also evaluating a referred sample, men were more affected than women, even when the higher male frequency for TBI was taken into account. The authors speculated if the 
higher incidence of neurodevelopment disorders or more brain lateralization on males would be explanations for this finding. Arciniegas and colleagues (2003) pointed out the age of onset of the disorder, between 26 and 33 years old, which is about 10 years later than the average age for the beginning of schizophrenia. This may reflect a different etiological process. Prodome symptoms may be common, and they include depression, antisocial and inappropriate social behavior, social withdrawal, and deterioration at work (Zhang and Sachdev 2003).

\section{Neuropsychiatric findings}

Fujii and Ahmed (2004) conducted a comparison between patients with schizophrenia and patients with psychosis after TBI who were referred for neuropsychological testing. Both groups presented deficits, but patients with psychosis after TBI were affected in more functions and in a more global manner. The same authors conducted an analysis of 69 published cases in the literature (Fujii and Ahmed 2002a). About $70 \%$ of these patients had electroencephalographic abnormalities, especially within temporal lobes, and almost $30 \%$ had seizures. The significance of these associations has not been clarified yet. Most of patients also had focal lesions or brain atrophy on CT or MRI, especially within frontal and temporal lobes. Other studies had already found a high proportion of frontal or temporal injuries in patients with psychosis after TBI (Achte 1969; Buckley et al 1993; Sachdev et al 2001). Subjects with neurological diseases or previous TBI may be more susceptible to the arising of psychotic symptoms after a new head injury (Fujii and Ahmed 2001).

The study of psychosis after TBI can reveal clues about the pathophysiology of primary psychotic disorders (Arcieniegas et al 2003). Within this context, Fujii and Ahmed (2002b) proposed a neurobiological model for psychosis in general. They suggested that delusions and hallucinations would have a similar nature than neurological symptoms such as aphasia, apraxia, or acalculia, for instance. The psychotic symptoms would be a result of the impairment of neural structures in a defined local, which would configure a neurobiological syndrome. According to these authors, psychoses in general would be associated to the dysfunction of the frontal systems, the temporal lobe, and the neurotransmission pathways that are projected in these areas. A rupture of the regulation among these systems would lead to a relative increase of the temporal limbic activity. All the individuals would be virtually susceptible, but those who have a genetic predisposition would have a lower threshold for the emerging of the symptoms when they are exposed to environmental risk factors (TBI, substance abuse) or even during their normal neurodevelopment. Among the supports for this theory there would be other conditions that are related to fronto-temporal damage and also to psychosis, such as Alzheimer's disease and temporal lobe epilepsy. The authors' hypothesis is certainly interesting, but nowadays there is not enough evidence to draw solid conclusions on the pathophysiology of psychosis after TBI. The area is quite controversial and plagued by limitations, mainly lack of operational diagnostic criteria and studies with small samples or selection bias. In fact, although TBI can be attributed exclusively to an external factor, the response to the event can vary depending on the innate biological characteristics of the individual. Therefore, like most of the pathologies, the psychiatric disorders associated to TBI, including the psychosis, can have a multifactorial etiology, whose genetic factors have a nonmendelian nature (Caspi and Moffitt 2006).

\section{Other findings}

As far as we know, no studies have directly approached psychosocial factors in psychosis after TBI. In the study by Fujii and Ahmed (2004), differences with regard to educational level and history of drug abuse were not found. Findings about symptomatology and course of disease were mentioned in the diagnosis section.

\section{Treatment}

There are only case reports in the literature about the pharmacotherapy on psychosis after TBI, which describe mostly the use of antipsychotics. However, typical antipsychotics that have anticholinergic, hypotensive, or sedative effects, or a strong dopaminergic antagonism are potentially able to worsen the already existent deficits for TBI survivors. It is possible that drugs such as haloperidol delay the neuronal recuperation (Feeney et al 1982; Goldstein 1993) and worsen the patients' prognosis in the short term (Rao et al 1985). Therefore, atypical antipsychotics seem to be more appropriate. The initial doses must be prescribed from one third to half of the usual ones, increasing them gradually and carefully, since these individuals are particularly susceptible to side effects (Arciniegas et al 2003). Well succeeded treatments using risperidone (Schreiber et al 1998) and olanzapine (Arciniegas et al 2003; Warden et al 2006) were reported, as well as the association between risperidone with galantamine (Bennouna et al 2005). The use of clozapine was also described (Michals et al 1993), but the side effects' profile can be adverse. 


\section{Disorders related to alcohol Diagnosis and epidemiology}

Alcohol is a worldwide used psychoactive substance which has a well-known participation in traffic accidents, falls, and violence. Since all these situations are TBI causes, it is not surprising that the disorders related to alcohol and TBI are frequently associated medical conditions. Standard instruments like the SCID or the CAGE questionnaire can be useful for detecting alcohol problems for TBI survivors (Ashman et al 2004).

Jorge and colleagues (2005) utilized the SCID to diagnose alcohol misuse in 158 TBI survivors. A history of alcohol dependence and abuse in the year previous to the traumatism was identified in $24.1 \%$ and $10.8 \%$ of the patients, respectively. One year after TBI, $60 \%$ of the patients who had alcohol misuse had sustained abstinence, but the validity of this rate was limited by loss to follow-up (almost half of the cases). In a population-based study, Horner and colleagues (2005) interviewed by phone more than 1600 individuals one year after TBI. Heavy use of alcohol was reported for $15.4 \%$ of the cases, moderate use for $14.3 \%$, and abstinence or infrequent use for $70.3 \%$. Both studies showed significantly higher rates of alcohol related-problems for men. The course of alcohol and other psychoactive substances use were examined by Kreutzer and colleagues (1996b) in young individuals (16 to 20 years old) who had suffered TBI. Before the trauma, $51 \%$ of the patients were classified as moderate or heavy drinkers. In the first months after TBI an increase in the number of abstinent individuals was observed, followed by a tendency for a return to the previous pattern of alcoholic ingestion. In a more recent study, similar patterns were observed for other substances (Ponsford et al 2007). The authors concluded that as the independence of the patients in the rehabilitation process increases, the use of alcohol is reinitiated. Thus, patients who had a previous history of moderate or heavy alcohol ingestion must receive special attention. Other studies demonstrated that, at the time of the traumatism, from one third up to half of the individuals were intoxicated by alcohol, and more than $60 \%$ of them had alcohol or other drug abuse in the past (Corrigan 1995; Parry-Jones et al 2006).

\section{Neuropsychiatric findings}

Wild and colleagues (2004), using MRI, observed generalized brain atrophy in TBI patients with history of moderate or heavy use of alcohol, as well as the ones who were intoxicated by alcohol at the moment of traumatism. These subjects also had a poorer neuropsychological outcome. In the already cited study by Jorge and colleagues (2005), patients with previous history of alcohol misuse had reduction of prefrontal gray matter volume. Patients who did not resume alcohol misuse showed a greater frequency of focal brain lesions (contusions and extracanial hemorrhages), preferentially involving the prefrontal cortices and the anterior temporal lobes. The authors suggested that the behavioral disturbances resulting from these selective damages may increase the risk of alcohol relapse.

Neuronal loss related to alcohol was reported in the frontal cortex, hypothalamus, cerebellum, and possibly hippocampus, amygdale, and locus coeruleus (Harper 1998). Therefore, TBI represents an additional disturbance in a nervous system which is already impaired by the alcohol misuse. In the study by Baguley and colleagues (1997), TBI and alcohol use produced mild alterations in event-related potential testing, but changes were significantly greater when both conditions were combined.

\section{Other findings}

Alcohol use is related to a less favorable evolution in TBI, with more general and psychiatric medical comorbidity, and also more difficulties from the neuropsychological and functional point of view (Perry-Jones et al 2006). In the sample by Jorge and colleagues (2005), patients with previous history of alcohol misuse had lower educational and socioeconomic status, poorer social and vocational functioning and restricted premorbid social support networks. Patients who did not sustain abstinence after TBI had lower educational level, higher TBI severity, and more mood disorders. Analysis of the individual variables showed that the occurrence of mood disorders and a history of alcohol misuse were associated to poor vocational outcome (Jorge et al 2005). In the study by Horner and colleagues (2005), heavy use of alcohol was associated to younger age, abuse of substances before the TBI, depression, and less physical limitations. Walker and colleagues (2003) analyzed 661 questionnaires filled in by individuals with substance dependence. Those who had reported previous TBI had more depression, anxiety, suicidal thoughts, violent behavior, difficulties for concentration, and use of cannabis. In another study (Felde et al 2006), the presence of substance-related disorders in patients with TBI was associated to higher rates of depressive and anxiety symptoms, antisocial personality, and suicidal attempts. Among those individuals with TBI history who committed suicide, alcohol abuse or dependence was pointed out as a possible predictive factor (Mainio et al 2007). 
Alcohol misuse was also reported as a possible result of other disorders that were caused by brain injuries. Beresford and colleagues (2005) described a group of patients who complained about affective lability after TBI, and that reported symptomatic relief when ingesting alcohol. When they were pharmacologically treated for affective lability, $90 \%$ of them maintained abstinence.

\section{Treatment}

Rehabilitation programs and pharmacologic treatment for comorbidity between TBI and alcohol related disorders must be adapted to the specific deficits and needs that are observed in these subjects (Jorge et al 2005). The methods that are used for the initial therapeutic engagement for other populations may not be appropriate for TBI survivors. For example, Corrigan and colleagues (2005) found low effectiveness in the brief motivational interview, which may reflect the cognitive difficulties of these individuals. On the other hand, Bombardier and colleagues (1997) described greater contemplation of change and readiness to take action to change alcohol use after TBI. According to the author, this may represent a window of opportunity to reduce post-injury alcohol misuse through motivational interviewing techniques.

\section{Personality changes Apathy}

Recently, apathy has been classified as the milder extreme of the disorders of diminished motivation, a pathological spectrum which also includes abulia and akinetic mutism, in increasing order of severity. These disorders must be differentiated from those conditions in which a reduction of the general activity occurs (for example, coma, delirium, aprosodia, catatonia, psychomotor retardation, akinesia) and from the conditions that present a reduction of the general activity and motivation (for example, dementia, depression). Differently from apathy, depression is a dysphoric state and suffering is usually reported by the patients, associated to a pessimistic view of themselves and the future (Marin and Wilkosz 2005). This concept can be enhanced by the lack of spontaneity in apathy, being different from the lack of interest in depression (Prigatano 1992).

Pelegrín-Valero and colleagues (2001) evaluated 55 consecutive patients one year after severe TBI. Neuropsychological tests were performed and the data served as a base for the diagnosis according to the DSV-IV. The criteria of personality changes due to TBI were filled in by $60 \%$ of the patients and apathy was the most prevalent symptom, in $34.5 \%$ of the sample. Kant and colleagues (1998) utilized the
Apathy Evaluation Scale (Marin et al 1991) in a sample of 83 TBI survivors from a neuropsychiatric clinic, finding apathy without depressive symptoms in $10.8 \%$ and apathy associated to depressive symptoms in up to $60 \%$. Younger patients or those with more severe traumatism presented more apathy without depressive symptoms, while older patients showed more associated depression. Andersson and colleagues (1999) evaluated patients from a rehabilitation clinic who had suffered TBI, vascular insult, or hypoxic brain damage. Among the 28 TBI subjects, apathy prevalence reached $46.4 \%$. Among all patients, subcortical or right hemisphere injuries were more related to a higher occurrence of apathy than injuries in the left hemisphere, as well as subcortical injuries were also more related to apathy than injuries in both hemispheres. The authors pointed out that the association of apathy to the location of the injuries is an evidence of the neurobiological bases of the symptom, in contrast with the possible psychological and social causes after the TBI. It is important to mention that these samples included patients with particularly severe sequelae, and the results may not be applicable to less specific populations.

Cortico-striatal-pallidal-thalamic pathways, enclosing the anterior cingulate cortex, accumbens nucleus, ventral pallidum, and medial dorsal thalamic nucleus, are considered mediators of motivation. The damage in these circuits produces akinetic mutism, abulia, and apathy, according to the severity of the dysfunction (Mega and Cohenour 1997). The orbitofrontal cortex, amygdala, hippocampus, and tegmental ventral area are also involved in the motivational state related to the environmental rewards. Impairment of the function in these structures may produce apathetic symptoms. For instance, Klüver-Bucy syndrome, in which the amygdalae is affected, or amnestic disorder and Alzheimer disease, in which the hippocampus is affected, are examples of conditions with relevant apathetic symptoms. Dopamine is considered linked to apathy because of its role in the mechanisms of novelty seeking, reward and response to unexpected events. Additionally, dopaminergic antagonists increase apathy, and agonists reduce it (Marin and Wilkosz 2005).

The treatment for akinetic mutism and abulia is essentially pharmacological. However, patients with apathy preserve some cognitive and communicative capacity, allowing psychological and environmental interventions A familiar environment with an increase of the stimulation and interest sources, as well as the support of a caregiver who stimulates the preserved abilities can be helpful. The pharmacological strategies initially enclose the optimization of the general health situation, the treatment of comorbidities 
(including depression) and the reduction or withdrawal of drugs that may worsen the symptoms (for example, dopaminergic antagonists, SSRIs). Drugs that are able to improve motivation, such as stimulants (dextroamphetamine, methylphenidate), activating antidepressants (bupropion, protriptyline, tranilcipromine, venlafaxin), dopaminergic agonists (amantadine, bromocriptine, levodopa-carbidopa, selegiline, pergolide, pramipexole) or cholinesterase inhibitors (donezepil, galantamine, rivastigmine) can be tried (Marin and Wilkosz 2005).

\section{Affective lability}

Different descriptions for affective lability after brain injuries are found in the literature. Some of them use terms such as emotional instability or rapid mood changes, referring in general to sudden variations in the behavior and emotions, without considering any distinction between mood and affect or the relationship between them and the environmental stimuli. In a more specific manner, and closer to the DSM-IV-TR terminology, other authors refer to the involuntary emotional expression disorder, in a continuum starting at normal affective variation, going through affective lability, and ending at pathological laughing and crying (Arciniegas et al 2005). There are no specific definitions for this syndrome in the current psychiatric diagnostic systems. Cunnings and colleagues (2006) proposed a series of criteria that can be summed up as laughing or crying episodes, or similar manifestations, resulting from brain injury, which represent a change in the previous emotional reactivity, and that are excessive, unrelated to the subjacent mood or independent from usual provoking stimuli.

Using similar criteria, Tateno and colleagues (2004) diagnosed pathological laughing and crying in $10.9 \%$ of 91 consecutive TBI patients. Severity was evaluated by the Pathological Laughter and Crying Scale (Robinson et al 1993). The syndrome was correlated to aggression and anxiety, but not to depression. The cases also presented a higher frequency of injuries in the frontal lobe, especially in the left side. In a previous study, Zeilig and colleagues (1996) found the syndrome for $5 \%$ of the patients, but relation to focal lesions was not consistent. In the study by PelegrinValero and colleagues (2001), the prevalence of personality change-labile type reached $32.7 \%$.

The classical pathophysiological theories for the involuntary emotional expression disorder are based on the serial processing principles and the hierarchical organization of the central nervous system. Areas such as the prefrontal cortex, the anterior cingulate cortex and insular cortex produce inhibition on the brain stem and the amygdala, regulating the emotional experience (Rabins and Arciniegas 2007). It was also proposed that the impairment of cerebroponto-cerebellar paths causes incapacity for the cerebellar structures to get adjusted to the execution of laughing or crying according to the environmental context, resulting in an inappropriate or chaotic emotional expression (Parvizi et al 2001). Although diverse neurotransmission mechanisms may be involved, it is given a special importance to serotonin, dopamine and glutamate, which demonstrate to be targets with positive results in the pharmacologic therapy (Rabins and Arciniegas 2007).

The nonpharmacological treatment strategies include patients' and relatives' education, emphasizing the involuntary character of the condition. A cognitive-behavioral approach of the symptoms may also be useful (Brook 2007). Tricyclic antidepressants and SSRIs are pharmacological options, although the evidences are limited. Dopaminergic drugs (amantadine, levodopa, nomifensine) can also be tried out. The combination of dextrometorphane and quinidine produced a significant symptomatic improvement in controlled studies with lateral amyotrophic sclerosis and multiple sclerosis patients, possibly through glutamatergic antagonism mechanisms (Brooks 2007).

\section{Aggression}

The definition of aggression after brain injury has been already pointed out as problematic or poorly understood (Prigatano 1992; Kim et al 2007). Correlated terms such as agitation, anger and irritability are often used in this context. It was proposed that agitation would define better delirium manifestations, with specific cognitive and behavioral characteristics, while aggression would mean damaging, threatening or intimidating behavior (Sandel and Mysiw 1996). In general, it is possible to classify aggression as impulsive (relatively nonplanned and spontaneous) or premeditated. This distinction is relevant from the neurobiological point of view, although it has been weakly considered in the literature (Davidson et al 2000). Additional approaches that have been found in the literature include the episodic dyscontrol syndrome, with recurrent crises of out of proportion or no justified fury due to provocation or frustration (Gordon 1999), and the antisocial behavior due to brain injury, or "acquired sociopathy", which could also enclose the inconsideration for moral and social principles (Anderson et al 1999; Blair and Cipolotti 2000). Impulsivity and anger seem to be the main characteristics in aggression after TBI (Dyer et al 2006). 
Because of the definition difficulties and of the differences in the researchers' designs, it is difficult to determine the epidemiology and the factors associated to aggression after TBI, as well as to make comparisons among the studies. In the study by Pelegrín-Valero and colleagues (2001), the aggressive type of personality change was diagnosed in $16.4 \%$ of the sample. Tateno and colleagues (2003) evaluated prospectively consecutive TBI patients through a wellknown instrument, the Overt Aggression Scale (Yudofsky et al 1986). Aggressive behavior was found for $33.7 \%$ of the sample, against $11.5 \%$ of the control group. Baguley and colleagues (2006) found aggression for $25 \%$ of the individuals by using the same scale, but with a higher cutoff point and a retrospective design. In both last mentioned studies, the aggressive behavior was related to depression. However, other researches did not find this association (Grafman et al 1996; Wood and Liossi 2006). Preinjury aggressive behavior (Greve et al 1996) and frontal lobe damage (Grafman et al 1996; Tateno et al 2003) were related to aggression after TBI. Abuse of substances, male gender, TBI severity, intelligence level, and low socioeconomic premorbid status were factors inconsistently found among different studies (Rosenbaum et al 1994; Grafman et al 1996; Rapoport et al 2002; Tateno et al 2003; Wood and Liossi 2006; Baguley et al 2006).

Impulsive aggression may be a consequence of a failure in the regulation of negative emotions, such as anger, for example. Threatening environmental stimuli are transmitted to the amygdala, which makes projections to the basal ganglia, where they are integrated with information of the social context that comes from the orbitofrontal cortex. Appropriate behavioral responses can, therefore, be initiated through projections toward other cortical regions, hypothalamus or brain stem. Consequently, the orbitofrontal cortex and adjacent areas such as the dorsolateral prefrontal cortex and the anterior cingulate cortex modulate the activity of the amygdala, through inhibition. The prefrontal cortex (and its inhibitory function) can be also activated by stimuli that indicate the violation of social expectations, such as facial expression of anger in the others, for example, forming a regulatory mechanism that is perhaps lost in those patients with injuries in these areas. Structural or functional abnormalities in these regions or in the connections among them can increase the propensity to impulsive aggression (Davidson et al 2000). Serotonin is the most studied neurotransmitter in aggressive behavior (Higley et al 1996; Anderson and Silver 1998). The evidences for the involvement of serotonin are varied, including low level of metabolites in cerebrospinal fluid in psychiatric patients with aggression, polymorphisms in the triptophan-hydroxylase enzyme gene and blunted response to the pharmacological challenge with serotonergic agonists (Davidson et al 2000).

Considering the multifactorial nature of aggression, psychological and social variables that may contribute for this behavior to arise must be approached. The aggressive behavior is evidently disturbing in social life; therefore individuals that are close to the patients must obtain support. Behavioral psychotherapeutic techniques can be useful (Baguley et al 2006), as well as the identification and treatment of associated depression (Tateno et al 2003). The literature about the pharmacotherapy for aggression is wide but with limited evidence strength. The best evidences are available for the beta-blockers propanolol and pindolol, but other drugs such as tricyclic antidepressants, SSRIs, buspirone, valproic acid, lithium, carbamazepine, and methylphenidate are also options (Warden et al 2006).

\section{Other personality changes}

Behavioral disinhibition, which is characterized by the weak control of the impulses, is another group of symptoms that is quoted in the DSM-IV-TR. The reports in the literature describe hyperactivity, impulsive aggression, social inadequacy and inconsequent or immature behavior. Frequently, these patients end up filling in the criteria for secondary mania (Starkstein and Robinson 1997). Aberrant sexual behavior and hypersexuality, which are problems with a high family and social impact, are not rare (Simpson et al 1999). The behavioral disinhibition was a part of the symptomatology in the famous case of Phineas Gage (Damásio et al 1994). Other approaches for the syndrome also include moria, a sort of silly euphoria, and Witzelsucht, a tendency to tell inappropriate jokes (Rommel et al 1999). The behavioral disinhibition is attributed to the frontal lobe impairment, more specifically the orbitofrontal and basolateral cortex. These areas are able to modulate, according to the environmental context, the primary responses that come from other regions, such as the limbic system and the motor cortex (Starkstein and Robinson 1997).

The DSM-IV-TR also includes a paranoid type of personality change after TBI, with suspiciousness as its main characteristic or even paranoid ideation. This definition is problematic, since more predominant psychotic symptoms would better characterize the diagnosis for psychosis due TBI. Therefore, the occurrence rates rather vary in the literature (from 2 up to $48 \%$ ), even when using similar diagnostic instruments (Rapoport et al 2002; Frenisy et al 2006). 
Another aspect that has been pointed out in the personality changes after TBI is the self-awareness impairment. At the extreme level (anosognosia), patients are completely unaware of their acquired physical and neuropsychological deficits. Conservative estimates indicate that up to $30 \%$ of the individuals that suffered severe TBI present self-awareness impairment. The intensity of the condition changes throughout the time and the persistence of the problem may require diffuse bilateral brain dysfunctions (Prigatano 2005). Using CT, Sherer and colleagues (2005) related self-awareness impairment to the number of brain lesions, but not to their volume or location. In general, the evidence supports the idea that the higher the patients' perception about their limitations is, the better the prognosis in rehabilitation is (Ownsworth and Clare 2006). Therefore, a careful approach of the symptoms may help these patients. There can be an artificial division, especially in situations of partial impairment self-awareness, between the extent of the patients' denial about their difficulties, as a psychological defense mechanism, and the extent of their unawareness of their own situation. At the research level, structural and metabolic neuroimaging studies may differentiate these phenomena (Prigatano 2005).

The current classification systems make a distinction between personality changes due to a general medical condition and personality disorders. In spite of the nosologic definition, some studies evaluated the axis II through structured interviews, finding higher rates than in the general population (Hibbard et al 2000; Koponen et al 2002).

\section{Final comments}

The main findings described in this review are summarized in Table 1. The literature about psychiatric disorders after TBI is relatively vast but limited regarding unequivocal scientific evidence.

On the subject of nosology, current evidences do not allow the definition of diagnostic criteria able to identify if a psychiatric disorder is caused by TBI. As a consequence, it is difficult for researches to assess pathophysiological aspects of these conditions, which in turn may limit even more the development of such criteria. However, the DSM-IV-TR recommendations (close temporal relationship, atypical symptomatology, absence of additional explanations, for example) seem to be useful. The variation of the epidemiological data among studies is another remarkable issue. It may reflect different designs, different diagnostic instruments and criteria or, furthermore, different characteristics of the samples. Many studies used very heterogeneous samples and were also limited by size of the samples or selection bias. Other limitations such as the absence of a "gold-standard" or the lack of blinded outcome assessment are even more difficult to approach. The generalization of some results for mild TBI may be also problematic, since it is difficult to evaluate a representative sample of this population. The main lack of data lies in the pathophysiology, which is largely unknown. As described above, some authors hypothesized about a relevant role of the frontal lobe, since its impairment is a relatively frequent finding. Moreover, a similarity concerning to the pattern of neuroanatomic lesions in psychiatric disorders after TBI and psychiatric disorders secondary to other general medical conditions seems to exist. Since psychiatric manifestations after TBI enclose the main nosologic groups of psychiatry, they may constitute a model for the so-called primary psychiatric disorders. A very practical impact of the lack of knowledge in the area concerns pharmacotherapy, which remains still similar to the treatment of primary psychiatric disorders. Few studies approached the effect of psychiatric drugs in the short term and it is virtually unknown how TBI patients respond in a longer term. Table 2 summarizes the current state of knowledge.

Despite these limitations, a high amount of valid information for the patients' care is available. The 1 in the quality of the evidences seems to be the present tendency, since the most recent studies adopt a prospective design, more defined diagnostic criteria, and the evaluation is made by using standard instruments. Carrying out prospective studies through multivariate type analysis and developing prognostic models for psychiatric disorders associated to TBI are scientific immediate challenges. Such models should ideally contemplate clinical, demographic, biochemical, hormonal, neurochemical, neurosurgical, neuroimaging, and immunology variables. This approach will be successful only through an interdisciplinary work among researchers from the basic and clinical area. Finally, the external validity of these researches results must be exhaustively searched, through the replication of the findings in different populations.

\section{Acknowledgments}

This work was supported by CNPq (Brazilian Council for Scientific and Technologic Development, Brazil), FAPESC (Foundation for Scientific Research and Technology of Santa Catarina State), FEESC (Foundation for Education and Engineering of Santa Catarina). João Quevedo was a visitor 
Table I Summary of findings for psychiatric disorders after TBI

\begin{tabular}{|c|c|}
\hline Findings & References \\
\hline \multicolumn{2}{|l|}{ Depression } \\
\hline Incidence $15.3 \%-33 \%$ & Kim et al 2007 \\
\hline Prevalence $18.5 \%-61 \%$ & Kim et al 2007 \\
\hline Abnormalities on CT & Levin et al 2005 \\
\hline Lower bilateral hippocampal volume & Jorge et al 2007 \\
\hline Volume reduction of the left prefrontal grey matter & Jorge et al 2004 \\
\hline Left dorsolateral frontal and left basal ganglia lesions & Fedoroff et al 1992 \\
\hline Normal dexamethasone suppression test & Saran et al 1985 \\
\hline Unemployment & Seel et al 2003; Dikmen et al 2004; Jorge et al 2004 \\
\hline Poorer social functioning & Fedoroff et al 1992; Gomez-Hernandez et al 1997 \\
\hline Dissatisfaction with work; lack of close personal relationships & Gomez-Hernandez et al 1997 \\
\hline Less education; preinjury alcohol-related problems & Dikmen et al 2004 \\
\hline Lower economic status; aggression; anxiety & Jorge et al 2004; Jorge et al 1993 c \\
\hline \multicolumn{2}{|l|}{ Mania } \\
\hline Incidence 9\% & Jorge et al 1993b \\
\hline Prevalence $4.2 \%$ & van Reekum et al 2000 \\
\hline Higher rates for men & van Reekum et al 1996 \\
\hline Lesions in the temporal basal poles & Jorge et al I993b; Murai and Fujimoto 2003 \\
\hline Seizures; more irritable mood and less euphoria & Shukla et al 1987 \\
\hline Aggression & Shukla et al 1987; DelBello et al 1999 \\
\hline Family history of mood disorders & Robinson et al 1988 \\
\hline \multicolumn{2}{|l|}{ Obsessive-compulsive disorder } \\
\hline Prevalence $1.6 \%-15 \%$ & Hibbard et al 1998; Deb et al 1999 \\
\hline Oribitofrontal cortex, cingulate cortex and caudate nucleus damage & Berthier et al 200I; Bilgic et al 2004; Ogai et al 2005 \\
\hline Obsessive slowness; compulsive exercises practice; aggression & Berthier et al 200I \\
\hline \multicolumn{2}{|l|}{ Posttraumatic stress disorder } \\
\hline Incidence II.3\%-24\% & Bryant and Harvey 1998; Bombardier et al 1999 \\
\hline Prevalence $3 \%-27.1 \%$ & Bryant et al 2000; Glaesser et al 2004 \\
\hline Increase of $\mathrm{S}-\mathrm{IOOB}$ in the acute phase of TBI & Sojka et al 2006 \\
\hline Impaired quality of life and social function; chronic pain & Bryant et al 1999 \\
\hline Posttraumatic amnesia as a protective factor & $\begin{array}{l}\text { Sbordone and Liter 1995; Glaesser et al 2004; } \\
\text { Gil et al } 2005\end{array}$ \\
\hline Lack of insight as a protective factor & Willians et al 2002 \\
\hline Depression; anxiety & $\begin{array}{l}\text { Bombardier et al 1999; Bryant et al 1999; } \\
\text { Glaesser et al } 2004\end{array}$ \\
\hline \multicolumn{2}{|l|}{ Psychosis } \\
\hline Incidence $0.1 \%-9.8 \%$ & David and Prince 2007 \\
\hline Prevalence $0.7 \%$ & van Reekum et al 2000 \\
\hline Higher rates for men; previous TBI or neurological diseases & Fujii and Ahmed 200I \\
\hline Most cases within I year after TBI; EEG abnormalities; seizures & Fujii and Ahmed 2002a \\
\hline Damage in frontal and temporal lobes & $\begin{array}{l}\text { Achte 1969; Sachdev et al 200I; } \\
\text { Fujii and Ahmed 2002a }\end{array}$ \\
\hline Predominance of positive symptoms & Sachdev et al 200I \\
\hline Global cognitive impairment & Fujii and Ahmed 2004 \\
\hline \multicolumn{2}{|l|}{ Alcohol-related disorders } \\
\hline Prevalence before TBI $34.9 \%-51 \%$ & Kreutzer et al I996b; Jorge et al 2005 \\
\hline
\end{tabular}


Table I (Continued)

\begin{tabular}{|c|c|}
\hline Findings & References \\
\hline Higher rates for men & Horner et al 2005; Jorge et al 2005 \\
\hline Generalized brain atrophy & Wild et al 2004 \\
\hline Changes in event-related potential testing & Baguley et al 1997 \\
\hline Prefrontal cortex volume reduction; relapse in patients with focal lesions & Jorge et al 2005 \\
\hline Less education; poorer vocational and social functioning & Jorge et al 2005 \\
\hline Return to the previous pattern of use after some months of abstinence & Kreutzer et al 1996b; Ponsford et al 2007 \\
\hline Depression & Walker et al 2003; Jorge et al 2005 \\
\hline Suicide & Mainio et al 2007 \\
\hline \multicolumn{2}{|l|}{ Personality changes } \\
\hline \multicolumn{2}{|l|}{ Apathy } \\
\hline Prevalence $34.5 \%$ after severe TBI & Pelegrín-Valero et al 2001 \\
\hline Younger age; more severe TBI & Kant et al 1998 \\
\hline Subcortical damage & Anderson et al 1999 \\
\hline \multicolumn{2}{|l|}{ Affective lability } \\
\hline Prevalence $5 \%-32.7 \%$ & Zeilig et al 1996; Pelegrín-Valero et al 2001 \\
\hline Frontal lobe damage; aggression; anxiety & Robinson et al 1993 \\
\hline \multicolumn{2}{|l|}{ Aggression } \\
\hline Prevalence $16.4 \%-33.7 \%$ & Pelegrín-Valero et al 200I; Tateno et al 2003 \\
\hline Frontal lobe damage & Grafman et al 1996; Tateno et al 2003 \\
\hline Depression & Tateno et al 2003; Baguley et al 2006 \\
\hline Poor preinjury social functioning; substance abuse & Tateno et al 2003 \\
\hline
\end{tabular}

Table 2 Current state of knowledge on psychiatric disorders after TBI

\section{Diagnosis}

The current evidences do not allow the characterization of operational diagnostic criteria able to clearly define if a psychiatric disorder is caused by TBI.

The DSM-IV-TR recommendations, however, seem to be useful.

The lack of diagnostic criteria is marked on personality changes due TBI.

\section{Epidemiology and associated factors}

Incidence and prevalence rates were quite variable among studies.

Most studies used very heterogeneous samples.

Studies frequently have been limited by small samples, selection bias and loss to follow-up.

No studies had blind outcome assessment.

Except for PTSD, the role of TBI severity is poorly understood.

External validity of data is particularly limited on mild TBI.

Depression is the main psychiatric disorder after TBI.

Psychosocial factors seem to be relevant on depression after TBI.

\section{Pathophysiology}

Pathophysiological mechanisms of psychiatric disorders after TBI are largely unknown.

The psychiatric disorders after TBI may reveal clues about the mechanisms of the primary psychiatric disorders.

With regard to localization of brain damage, psychiatric disorders after TBI seem to have similarities compared to psychiatric disorders after other types of brain damage.

The frontal lobe may have an important role in the mechanism of the symptoms.

Neuroimaging findings are limited; no studies have approached functional methods.

\section{Treatment}

Most data derives from case reports and series.

Pharmacotherapy is still similar to the primary psychiatric disorders' one; special care may be needed with regard to side effects and drug interactions. 
professor at the NUPNEC-UFSC. Roger Walz is a researcher from the Cyclops Project, UFSC. The authors report no other conflicts of interest in this work.

\section{References}

Achte KA, Hillbom E, Aalberg V. 1969. Psychoses following war brain injuries. Acta Psychiatr Scand, 45:1-18.

Adler CM, DelBello MP, Strakowski SM. 2006. Brain network dysfunction in bipolar disorder. CNS Spectr, 11:312-20.

Alderfer BS, Arciniegas DB, Silver JM. 2005. Treatment of depression following traumatic brain injury. $J$ Head Trauma Rehabil, 20:544-62.

[APA] American Psychiatric Association. 2000. Diagnostic and statistical manual of mental disorders, 4th edition, text revision. Washington, DC: American Psychiatric Association.

Anderson K, Silver JM. 1998. Modulation of Anger and Aggression. Semin Clin Neuropsychiatry, 3:232-42.

Anderson SW, Bechara A, Damasio H, et al. 1999. Impairment of social and moral behavior related to early damage in human prefrontal cortex. Nat Neurosci, 2:1032-7.

Andersson S, Krogstad JM, Finset A. 1999. Apathy and depressed mood in acquired brain damage: relationship to lesion localization and psychophysiological reactivity. Psychol Med, 29:447-56.

Arciniegas DB, Harris SN, Brousseau KM. 2003. Psychosis following traumatic brain injury. Int Rev Psychiatry, 15:328-40.

Arciniegas DB, Lauterbach EC, Anderson KE, et al. 2005. The differential diagnosis of pseudobulbar affect (PBA). Distinguishing PBA among disorders of mood and affect. Proceedings of a roundtable meeting. CNS Spectr, 10:1-14.

Ashman TA, Schwartz ME, Cantor JB, et al. Screening for substance abuse in individuals with traumatic brain injury. Brain Inj, 18:191-202.

Bárcena-Orbe A, Rodríguez-Arias CA, Rivero-Martín B, et al. 2006. Overview of head injury. Neurocirugia (Astur), 17:495-518.

Baguley IJ, Felmingham KL, Lahz S, et al. 1997. Alcohol abuse and traumatic brain injury: effect on event-related potentials. Arch Phys Med Rehabil, 78:1248-53.

Baguley IJ, Cooper J, Felmingham K. 2006. Aggressive behavior following traumatic brain injury: how common is common? $J$ Head Trauma Rehabil, 21:45-56.

Bennouna M, Greene VB, Defranoux L. 2005. Adjuvant galantamine to risperidone improves negative and cognitive symptoms in a patient presenting with schizophrenialike psychosis after traumatic brain injury. $J$ Clin Psychopharmacol, 25:505-7.

Beresford TP, Arciniegas D, Clapp L, et al. 2005. Reduction of affective lability and alcohol use following traumatic brain injury: a clinical pilot study of anti-convulsant medications. Brain Inj, 19:309-13.

Berthier ML, Kulisevsky JJ, Gironell A, et al. 1996. Obsessivecompulsive disorder associated with brain lesions: clinical phenomenology, cognitive function, and anatomic correlates. Neurology, 47:353-61.

Berthier ML, Kulisevsky JJ, Gironell A, et al. 2001. Obsessive-compulsive disorder and traumatic brain injury: behavioral, cognitive, and neuroimaging findings. Neuropsychiatry Neuropsychol Behav Neurol, 14:23-31.

Bilgic B, Baral-Kulaksizoglu I, Hanagasi H, et al. 2004. Obsessive-compulsive disorder secondary to bilateral frontal damage due to a closed head injury. Cogn Behav Neurol, 17:118-20.

Binder S, Corrigan JD, Langlois JA. 2005. The public health approach to traumatic brain injury: an overview of CDC's research and programs. J Head Trauma Rehabil, 20:189-95.

Blair RJ, Cipolotti L. 2000. Impaired social response reversal. A case of 'acquired sociopathy'. Brain, 123(Pt 6):1122-41.

Bombardier CH, Ehde D, Kilmer J. 1997. Readiness to change alcohol drinking habits after traumatic brain injury. Arch Phys Med Rehabil, 78:592-6.
Bombardier CH, Fann JR, Temkin N, et al. 2006. Posttraumatic stress disorder symptoms during the first six months after traumatic brain injury. J Neuropsychiatry Clin Neurosci, 18:501-8.

Bowles AO. 2007. Acute brain injury survivor's management. J Trauma, 62(6 Suppl):S10.

Brooks BR. 2007. Involuntary emotional expression disorder: treating the untreated. CNS Spectr, 12(4 Suppl 5):23-7.

Bryant RA. 1996. Posttraumatic stress disorder, flashbacks, and pseudomemories in closed head injury. J Trauma Stress, 9:621-9.

Bryant RA. 2001. Posttraumatic stress disorder and traumatic brain injury: can they co-exist? Clin Psychol Ver, 21:931-48.

Bryant RA, Harvey AG. 1998. Relationship between acute stress disorder and posttraumatic stress disorder following mild traumatic brain injury. Am J Psychiatry, 155:625-9.

Bryant RA, Marosszeky JE, Crooks J, et al. 1999. Interaction of posttraumatic stress disorder and chronic pain following traumatic brain injury. J Head Trauma Rehabil, 14:588-94.

Bryant RA, Marosszeky JE, Crooks J, et al. 2000. Posttraumatic stress disorder after severe traumatic brain injury. Am J Psychiatry, 157:629-31.

Bryant RA, Marosszeky JE, Crooks J, et al. 2004. Elevated resting heart rate as a predictor of posttraumatic stress disorder after severe traumatic brain injury. Psychosom Med, 66:760-1.

Buckley P, Stack JP, Madigan C, et al. 1993. Magnetic resonance imaging of schizophrenia-like psychoses associated with cerebral trauma: clinicopathological correlates. Am J Psychiatry, 150:146-8.

Campbell S, MacQueen G. 2004. The role of the hippocampus in the pathophysiology of major depression. J Psychiatry Neurosci, 29:417-26.

Caspi A, Moffitt TE. 2006. Gene-environment interactions in psychiatry: joining forces with neuroscience. Nat Rev Neurosci, 7:583-90.

Childers MK, Holland D, Ryan MG, et al. 1998. Obsessional disorders during recovery from severe head injury: report of four cases. Brain Inj, 12:613-16.

Coetzer BR, Stein DJ. 2003. Obsessive-compulsive disorder following traumatic brain injury: diagnostic issues. $J$ Cogn Rehabil, 4:4-8.

Corrigan JD. 1995. Substance abuse as a mediating factor in outcome from traumatic brain injury. Arch Phys Med Rehabil, 76:302-9.

Corrigan JD, Bogner J, Lamb-Hart G, et al. 2005. Increasing substance abuse treatment compliance for persons with traumatic brain injury. Psychol Addict Behav, 19:131-9.

Creamer M, O’Donnell ML, Pattison P. 2005. Amnesia, traumatic brain injury, and posttraumatic stress disorder: a methodological inquiry. Behav Res Ther, 43:1383-9.

Cummings JL, Arciniegas DB, Brooks BR, et al. 2006. Defining and diagnosing involuntary emotional expression disorder. CNS Spectr, 11:1-7.

Damasio H, Grabowski T, Frank R, et al. 1994. The return of Phineas Gage: clues about the brain from the skull of a famous patient. Science, 264:1102-5.

David AS, Prince M. 2005. Psychosis following head injury: a critical review. J Neurol Neurosurg Psychiatry, 76(Suppl 1):i53-60.

Davidson RJ, Putnam KM, Larson CL. 2000. Dysfunction in the neural circuitry of emotion regulation - a possible prelude to violence. Science, 289:591-4.

Deb S, Lyons I, Koutzoukis C, et al. 1999. Rate of psychiatric illness 1 year after traumatic brain injury. Am J Psychiatry, 156:374-8.

DelBello MP, Soutullo CA, Zimmerman ME, et al. 1999. Traumatic brain injury in individuals convicted of sexual offenses with and without bipolar disorder. Psychiatry Res, 89:281-6.

Dikmen SS, Bombardier CH, Machamer JE, et al. 2004. Natural history of depression in traumatic brain injury. Arch Phys Med Rehabil, $85: 1457-64$

Dyer KF, Bell R, McCann J, et al. 2006. Aggression after traumatic brain injury: analysing socially desirable responses and the nature of aggressive traits. Brain Inj, 20:1163-73.

Elbert T, Schauer M. 2002. Psychological trauma: burnt into memory. Nature, 419:883. 
Fann JR, Burington B, Leonetti A, et al. 2004. Psychiatric illness following traumatic brain injury in an adult health maintenance organization population. Arch Gen Psychiatry, 61:53-61.

Fedoroff JP, Starkstein SE, Forrester AW, et al. 1992. Depression in patients with acute traumatic brain injury. Am J Psychiatry, 149:918-23.

Feeney DM, Gonzalez A, Law WA. 1982. Amphetamine, haloperidol, and experience interact to affect rate of recovery after motor cortex injury. Science, 217:855-7.

Felde AB, Westermever J, Thuras P. 2006. Co-morbid traumatic brain injury and substance use disorder: childhood predictors and adult correlates. Brain Inj, 20:41-9.

First MB, Spitzer RL, Gibbon M, et al. 1996. Structured Clinical Interview for DSM-IV Axis I Disorders, Clinical Version (SCID-CV). Washington, DC: Americam Psychiatric Press, Inc.

Frenisy MC, Benony H, Chahraoui K, et al. 2006. Brain injured patients versus multiple trauma patients: some neurobehavioral and psychopathological aspects. J Trauma, 60:1018-26.

Frey BN, Fonseca MM, Machado-Vieira R, et al. 2004. Neuropatological and neurochemical abnormalities in bipolar disorder. Rev Bras Psiquiatr, 26:180-8.

Fujii DE, Ahmed I. 2001. Risk factors in psychosis secondary to traumatic brain injury. J Neuropsychiatry Clin Neurosci, 13:61-9.

Fujii D, Ahmed I. 2002a. Characteristics of psychotic disorder due to traumatic brain injury: an analysis of case studies in the literature. $J$ Neuropsychiatry Clin Neurosci, 14:130-40.

Fujii D, Ahmed I. 2002b. Psychotic disorder following traumatic brain injury: a conceptual framework. Cognit Neuropsychiatry, 7:41-62.

Fujii D, Ahmed I, Hishinuma E. 2004. A neuropsychological comparison of psychotic disorder following traumatic brain injury, traumatic brain injury without psychotic disorder, and schizophrenia. J Neuropsychiatry Clin Neurosci, 16:306-14.

Fujii D, Ahmed I. 2004. Is psychosis a neurobiological syndrome? Can J Psychiatry, 49:713-18.

Glaesser J, Neuner F, Lütgehetmann R, et al. 2004. Posttraumatic Stress Disorder in patients with traumatic brain injury. BMC Psychiatry, 4:5.

Gil S, Caspi Y, Ben-Ari I, et al. 2005. Does memory of a traumatic event increase the risk for posttraumatic stress disorder in patients with traumatic brain injury? A prospective study. Am J Psychiatry, 162:963-9.

Gil S, Caspi Y, Ben-Ari I, et al. 2006. Memory of the traumatic event as a risk factor for the development of PTSD: lessons from the study of traumatic brain injury. CNS Spectr, 11:603-7.

Goldstein LB. 1993. Basic and clinical studies of pharmacologic effects on recovery from brain injury. J Neural Transplant Plast, 4:175-92.

Gomez-Hernandez R, Max JE, Kosier T, et al. 1997. Social impairment and depression after traumatic brain injury. Arch Phys Med Rehabil, 78:1321-6.

Gordon N. 1999. Episodic dyscontrol syndrome. Dev Med Child Neurol, 41:786-8.

Grados MA. 2003. Obsessive-compulsive disorder after traumatic brain injury. Int Rev Psychiatry, 15:350-8.

Grafman J, Schwab K, Warden D, et al. 1996. Frontal lobe injuries, violence, and aggression: a report of the Vietnam Head Injury Study. Neurology, 46:1231-8.

Graybiel AM, Rauch SL. 2000. Toward a neurobiology of obsessivecompulsive disorder. Neuron, 28:343-7.

Greve KW, Sherwin E, Stanford MS, et al. 2001. Personality and neurocognitive correlates of impulsive aggression in long-term survivors of severe traumatic brain injury. Brain Inj, 15:255-62.

Harper C. 1998. The neuropathology of alcohol-specific brain damage, or does alcohol damage the brain? J Neuropathol Exp Neurol, 57:101-10.

Hibbard MR, Uysal S, Kepler K, et al. 1998. Axis I psychopathology in individuals with traumatic brain injury. J Head Trauma Rehabil, 13:24-39.

Hibbard MR, Bogdany J, Uysal S, et al. 2000. Axis II psychopathology in individuals with traumatic brain injury. Brain Inj, 14:45-61.
Higley JD, Mehlman PT, Poland RE, et al. 1996. CSF testosterone and 5-HIAA correlate with different types of aggressive behaviors. Biol Psychiatry, 40:1067-82.

Horner MD, Ferguson PL, Selassie AW, et al. 2005. Patterns of alcohol use 1 year after traumatic brain injury: a population-based, epidemiological study. J Int Neuropsychol Soc, 11:322-30.

Jenike M, Brandon A. 1988. Obsessive-compulsive disorder and head trauma: A rare association. J Anxiety Disord, 4:353-9.

Jorge RE, Robinson RG, Arndt S, 1993a. Are there symptoms that are specific for depressed mood in patients with traumatic brain injury? J Nerv Ment Dis, 181:91-9.

Jorge RE, Robinson RG, Starkstein SE, et al. 1993b. Secondary mania following traumatic brain injury. Am J Psychiatry, 150:916-21.

Jorge RE, Robinson RG, Starkstein SE, et al. 1993c. Depression and anxiety following traumatic brain injury. $J$ Neuropsychiatry Clin Neurosci, 5:369-74

Jorge RE, Robinson RG, Moser D, et al. 2004. Major depression following traumatic brain injury. Arch Gen Psychiatry, 61:42-50.

Jorge RE, Starkstein SE. 2005. Pathophysiologic aspects of major depression following traumatic brain injury. J Head Trauma Rehabil, 20:475-87.

Jorge RE, Starkstein SE, Arndt S, et al. 2005. Alcohol misuse and mood disorders following traumatic brain injury. Arch Gen Psychiatry, 62:742-9.

Jorge RE, Acion L, Starkstein SE, et al. 2007. Hippocampal volume and mood disorders after traumatic brain injury. Biol Psychiatry, 62:332-8.

Joseph S, Masterson J. 1999. Posttraumatic stress disorder and traumatic brain injury: are they mutually exclusive? J Trauma Stress, 12:437-53.

Kant R, Smith-Seemiller L, Duffy JD. 1996. Obsessive-compulsive disorder after closed head injury: review of literature and report of four cases. Brain Inj, 10:55-63.

Kant R, Duffy JD, Pivovarnik A. 1998. Prevalence of apathy following head injury. Brain Inj, 12:87-92.

Kant R, Coffey CE, Bogyi AM. 1999. Safety and efficacy of ECT in patients with head injury: a case series. J Neuropsychiatry Clin Neurosci, 11:32-7.

Kim E, Lauterbach EC, Reeve A, et al. 2007. Neuropsychiatric complications of traumatic brain injury: a critical review of the literature (a report by the ANPA Committee on Research). J Neuropsychiatry Clin Neurosci, 19:106-27.

Koponen S, Taiminen T, Portin R, et al. 2002. Axis I and II psychiatric disorders after traumatic brain injury: a 30-year follow-up study. Am $J$ Psychiatry, 159:1315-21.

Kreutzer JS, Marwitz JH, Seel R, et al. 1996a. Validation of a neurobehavioral functioning inventory for adults with traumatic brain injury. Arch Phys Med Rehabil, 77:116-24.

Kreutzer JS, Witol AD, Marwitz JH. 1996b. Alcohol and drug use among young persons with traumatic brain injury. J Learn Disabi, 29:643-51.

Langlois JA, Rutland-Brown W, Thomas KE. 2006. Traumatic brain Injury in the United States: emergency department visits, hospitalizations, and deaths. Atlanta: Centers for Disease Control and Prevention, National Center for Injury Prevention and Control.

Levin HS, McCauley SR, Josic CP, et al. 2005. Predicting depression following mild traumatic brain injury. Arch Gen Psychiatry, 62:523-8.

Mainio A, Kyllonen T, Viilo K, et al. 2007. Traumatic brain injury, psychiatry disorders and suicide: A population-based study of suicide victims during the years 1988-2004 in Northern Finland. Brain Inj, $21: 851-5$

Malaspina D, Goetz RR, Friedman JH, et al. 2001. Traumatic brain injury and schizophrenia in members of schizophrenia and bipolar disorder pedigrees. Am J Psychiatry, 158:440-6.

Marin RS, Biedrzycki RC, Firinciogullari S. 1991. Reliability and validity of the Apathy Evaluation Scale. Psychiatry Res, 38:143-62. 
Marin RS, Wilkosz PA. 2005. Disorders of diminished motivation. J Head Trauma Rehabil, 20:377-88.

Masini M. 1994. Epidemiological study of head injuries in the Federal District of Brazil. J Bras Neurocirug, 5:61-8.

Mayou R, Bryant B, Duthie R. 1993. Psychiatric consequences of road traffic accidents. Br Med J, 307:647-51.

McKeon J, McGuffin P, Robinson P. 1984. Obsessive-compulsive neurosis following head injury: a report of four cases. Br J Psychiatry, 144:190-2.

McMillan TM, Williams WH, Bryant R. 2003. Post-traumatic stress disorder and traumatic brain injury: a review of causal mechanisms, assessment and treatment. Neuropsychol Rehabil, 13(1/2):149-64.

Mega MS, Cohenour RC. 1997. Akinetic mutism: disconnection of frontal-subcortical circuits. Neuropsychiatry Neuropsychol Behav Neurol, 10:254-9.

Melo JR, Silva RA, Moreira ED. 2004. Characteristics of patients with head injury at Salvador City. Arq Neuropsiquiatr, 62(3A):711-4.

Michals ML, Crismon ML, Roberts S, et al. 1993. Clozapine response and adverse effects in nine brain-injured patients. J Clin Psychopharmacol, 13:198-203.

Murai T, Fujimoto S. 2003. Rapid cycling bipolar disorder after left temporal polar damage. Brain Inj, 17:355-8.

Neylan TC. 2000. Neuropsychiatric consequences of traumatic brain injury: observations from Adolf Meyer. J Neuropsychiatry Clin Neurosci, 12:406.

Nortje J, Menon DK. 2004. Traumatic brain injury: physiology, mechanisms, and outcome. Curr Opin Neurol, 17:711-18.

Nutt D. 1999. Alcohol and the brain. Pharmacological insights for psychiatrists. Br J Psychiatry, 175:114-19.

Ogai M, Iyo M, Mori N, et al. 2005. A right orbitofrontal region and OCD symptoms: a case report. Acta Psychiatr Scand, 111:74-6.

Oster TJ, Anderson CA, Filley CM, et al. 2007. Quetiapine for mania due to traumatic brain injury. CNS Spectr, 12:764-9.

Ownsworth T, Clare L. 2006. The association between awareness deficits and rehabilitation outcome following acquired brain injury. Clin Psychol Rev, 26:783-95.

Paradiso S, Chemerinski E, Yazici K, et al. 1999. Frontal lobe syndrome reassessed: comparison of patients with lateral or medial frontal brain damage. J Neurol Neurosurg Psychiatry, 67:664-7.

Parry-Jones BL, Vaughan FL, Miles Cox W. 2006. Traumatic brain injury and substance misuse: a systematic review of prevalence and outcomes research (1994-2004). Neuropsychol Rehabil, 16:537-60.

Parvizi J, Anderson SW, Martin CO, et al. 2001. Pathological laughter and crying: a link to the cerebellum. Brain, 124(Pt 9):1708-19.

Pelegrín-Valero CA, Gómez-Hernández R, Muñoz-Céspedes JM, et al. 2001. Nosologic aspects of personality change due to head trauma. Rev Neurol, 32:681-7.

Perna RB, Rouselle A, Brennan P. 2003. Traumatic brain injury: depression, neurogenesis, and medication management. J Head Trauma Rehabil, 18:201-3.

Ponsford J, Whelan-Goodinson R, Bahar-Fuchs A. 2007. Alcohol and drug use following traumatic brain injury: a prospective study. Brain Inj, 21(13-14):1385-92.

Prigatano GP. 1992. Personality disturbances associated with traumatic brain injury. J Consult Clin Psychol, 60:360-8.

Prigatano GP. 2005. Disturbances of self-awareness and rehabilitation of patients with traumatic brain injury: a 20 -year perspective. $J$ Head Trauma Rehabil, 20:19-29.

Rabins PV, Arciniegas DB. 2007. Pathophysiology of involuntary emotional expression disorder. CNS Spectr, 12(4 Suppl 5):17-22.

Rao N, Jellinek HM, Woolston DC. 1985. Agitation in closed head injury: haloperidol effects on rehabilitation outcome. Arch Phys Med Rehabil, 66:30-4

Rapoport M, McCauley S, Levin H, et al. 2002. The role of injury severity in neurobehavioral outcome 3 months after traumatic brain injury. Neuropsychiatry Neuropsychol Behav Neurol, 15:123-32.
Rapoport MJ, McCullagh S, Streiner D, et al. 2003. The clinical significance of major depression following mild traumatic brain injury. Psychosomatics, 44:31-7.

Rapoport MJ, Chan F, Lanctot K, et al. 2008. An open-label study of citalopram for major depression following traumatic brain injury. $J$ Psychopharmacol, 2008 Jan 21; [Epub ahead of print]

Richardson RM, Sun D, Bullock MR. 2007. Neurogenesis after traumatic brain injury. Neurosurg Clin N Am, 18:169-81, xi.

Riess H, Schwartz CE, Klerman GL. 1987. Manic syndrome following head injury: another form of secondary mania. J Clin Psychiatry, 48:29-30.

Robinson RG, Boston JD, Starkstein SE, et al. 1998. Comparison of mania and depression after brain injury: causal factors. Am J Psychiatry, 145:172-8.

Robinson RG, Parikh RM, Lipsey JR, et al. 1993. Pathological laughing and crying following stroke: validation of a measurement scale and a double-blind treatment study. Am J Psychiatry, 150:286-93.

Rola R, Mizumatsu S, Otsuka S, et al. 2006. Alterations in hippocampal neurogenesis following traumatic brain injury in mice. Exp Neurol, 202:189-99.

Rommel O, Widdig W, Mehrtens S, et al. 1999. Frontal lobe syndrome caused by severe head trauma or cerebrovascular diseases. Nervenarzt, 70:530-8.

Rosenthal M, Christensen BK, Ross TP. 1998. Depression following traumatic brain injury. Arch Phys Med Rehabil, 79:90-103.

Sachdev P, Smith JS, Cathcart S. 2001. Schizophrenia-like psychosis following traumatic brain injury: a chart-based descriptive and casecontrol study. Psychol Med, 31:231-9.

Sandel ME, Mysiw WJ. 1996. The agitated brain injured patient. Part 1: Definitions, differential diagnosis, and assessment. Arch Phys Med Rehabil, 77:617-23.

Saran AS. 1985. Depression after minor closed head injury: role of dexamethasone suppression test and antidepressants. J Clin Psychiatry, 46:335-8.

Sbordone RJ, Liter JC. 1995. Mild traumatic brain injury does not produce post-traumatic stress disorder. Brain Inj, 9:405-12.

Schneck CD. 2002. Bipolar disorder in neurologic illness. Curr Treat Options Neurol, 4:477-86.

Schreiber S, Klag E, Gross Y, et al. 1998. Beneficial effect of risperidone on sleep disturbance and psychosis following traumatic brain injury. Int Clin Psychopharmacol, 13:273-5.

Seel RT, Kreutzer JS, Rosenthal M, et al. 2003. Depression after traumatic brain injury: a National Institute on Disability and Rehabilitation Research Model Systems multicenter investigation. Arch Phys Med Rehabil, 84:177-84.

Servadei F, Antonelli V, Betti L, et al. 2002. Regional brain injury epidemiology as the basis for planning brain injury treatment. The Romagna (Italy) experience. Neurosurg Sci, 46(3-4):111-19.

Sherer M, Hart T, Whyte J, et al. 2005. Neuroanatomic basis of impaired selfawareness after traumatic brain injury: findings from early computed tomography. J Head Trauma Rehabil, 20:287-300.

Shukla S, Cook BL, Mukherjee S, et al. 1987. Mania following head trauma. Am J Psychiatry, 144:93-6.

Simpson G, Blaszczynski A, Hodgkinson A. 1999. Sex offending as a psychosocial sequela of traumatic brain injury. J Head Trauma Rehabil, 14:567-80.

Sliwinski M, Gordon WA, Bogdany J. 1998. The Beck Depression Inventury: is it a suitable measure of depression for individuals with traumatic brain injury? J Head Trauma Rehabil, 13:40-6.

Soblosky JS, Rogers NL, Adams JA, et al. 1992. Central and peripheral biogenic amine effects of brain missile wounding and increased intracranial pressure. J Neurosurg, 76:119-26.

Sojka P, Stalnacke BM, Björnstig U, et al. 2006. One-year follow-up of patients with mild traumatic brain injury: occurrence of post-traumatic stress-related symptoms at follow-up and serum levels of cortisol, S-100B and neuron-specific enolase in acute phase. Brain Inj, 20:613-20. 
Starkstein SE, Boston JD, Robinson RG. 1988. Mechanisms of mania after brain injury: 12 case reports and review of the literature. J Nerv Ment Dis, 176:87-100.

Starkstein SE, Pearlson GD, Boston J, et al. 1987. Mania after brain injury. A controlled study of causative factors. Arch Neurol, 44:1069-73.

Starkstein SE, Robinson RG. 1997. Mechanism of disinhibition after brain lesions. J Nerv Ment Dis, 185:108-14.

Stengler-Wenzke K, Muller U. 2002. Fluoxetine for OCD after brain injury. Am J Psychiatry, 159:872.

Sumpter RE, McMillan TM. 2005. Misdiagnosis of post-traumatic stress disorder following severe traumatic brain injury. Br J Psychiatry, 186:423-6.

Tagliaferri F, Compagnone C, Korsic M, et al. 2006. A systematic review of brain injury epidemiology in Europe. Acta Neurochir (Wien), 148:255-68.

Tateno A, Jorge RE, Robinson RG. 2003. Clinical correlates of aggressive behavior after traumatic brain injury. JNeuropsychiatry Clin Neurosci, 15:155-60.

Teasdale G, Jennett B. 1974. Assessment of coma and impaired consciousness. A practical scale. Lancet, 2(7872):81-4.

Thomsen IV. 1984. Late outcome of very severe blunt head trauma: a 10-15 year second follow-up. J Neurol Neurosurg Psychiatry, 47:260-8.

Turner-Stokes L, MacWalter R. 2005. Use of antidepressant medication following acquired brain injury: concise guidance. Clin Med, 5:268-74.

Van Reekum R, Cohen T, Wong J. 2000. Can traumatic brain injury cause psychiatric disorders? J Neuropsychiatry Clin Neurosci, 12:316-27.

Van Reekum R, Bolago I, Finlayson MA, et al. 1996. Psychiatric disorders after traumatic brain injury. Brain Inj, 10:319-27.

Vassallo JL, Proctor-Weber Z, Lebowitz BK, et al. 2007. Psychiatric risk factors for traumatic brain injury. Brain Inj, 21:567-73.
Vieweg WV, Julius DA, Fernandez A, et al. 2006. Posttraumatic stress disorder: clinical features, pathophysiology, and treatment. Am J Med, 119:383-90.

Wada A, Yokoo H, Yanagita T, et al. 2005. Lithium: potential therapeutics against acute brain injuries and chronic neurodegenerative diseases. $J$ Pharmacol Sci, 99:307-21.

Warden DL, Gordon B, McAllister TW, et al. 2006. Guidelines for the pharmacologic treatment of neurobehavioral sequelae of traumatic brain injury. J Neurotrauma, 23:1468-501.

Walker R, Hiller M, Staton M, et al. 2003. Head injury among drug abusers: an indicator of co-occurring problems. J Psychoactive Drugs, 35:343-53.

Wilde EA, Bigler ED, Gandhi PV, et al. 2004. Alcohol abuse and traumatic brain injury: quantitative magnetic resonance imaging and neuropsychological outcome. J Neurotrauma, 21:137-47.

Williams WH, Evans JJ, Needham P, et al. 2002. Neurological, cognitive and attributional predictors of posttraumatic stress symptoms after traumatic brain injury. J Trauma Stress, 15:397-400.

Wood RL, Liossi C. 2006. Neuropsychological and neurobehavioral correlates of aggression following traumatic brain injury. J Neuropsychiatry Clin Neurosci, 18:333-41.

World Health Organization. 1992. The ICD-10 classification of mental and behavioural disorders: clinical descriptions and diagnostic guidelines. Geneva: World Health Organization.

Yudofsky SC, Silver JM, Jackson W, et al. 1986. The Overt Aggression Scale for the objective rating of verbal and physical aggression. Am J Psychiatry, 143:35-9.

Zeilig G, Drubach DA, Katz-Zeilig M, et al. 1996. Pathological laughter and crying in patients with closed traumatic brain injury. Brain Inj, 10:591-7.

Zhang Q, Sachdev PS. 2003. Psychotic disorder and traumatic brain injury. Curr Psychiatry Rep, 5:197-201. 